\title{
Costs associated with rheumatoid arthritis in Italy: past, present, and future
}

This article was published in the following Dove Press journal:

ClinicoEconomics and Outcomes Research

10 February 2016

Number of times this article has been viewed

\author{
Maurizio Benucci' \\ Veronica Rogai ${ }^{2}$ \\ Fabiola Atzeni ${ }^{3}$ \\ Volker Hammen ${ }^{4}$ \\ Piercarlo Sarzti-Puttini ${ }^{3}$ \\ Alberto Migliore ${ }^{5}$ \\ 'Rheumatology Unit, S.Giovanni di \\ Dio Hospital, Florence, Italy; ${ }^{2}$ Eli Lilly \\ Italia SpA, Sesto Fiorentino, Italy; \\ ${ }^{3}$ Rheumatology Unit, L Sacco Hospital, \\ Milan, Italy; ${ }^{4}$ Lilly Deutschland $\mathrm{GmbH}$, \\ Bad Homburg, Germany; ${ }^{5}$ Villa San \\ Pietro Fatebenefratelli Hospital, \\ Rome, Italy
}

Correspondence: Maurizio Benucci Unità di Reumatologia, Azienda Sanitaria di Firenze, Ospedale San Giovanni di Dio, Via Torregalli 3, 50143 Firenze, Italy Tel +390557192331 Fax +390557192306

Email maubenucci@tiscali.it, maurizio. benucci@asf.toscana.it

\begin{abstract}
This literature review examines available evidence on the current and past costs associated with rheumatoid arthritis (RA) in Italy, together with the future health-economic prospects for the disease. Studies have been conducted to date on the prevalence, or the associated costs, of RA in Italy. Although future changes in the incidence of RA are a matter of debate, the impact of RA on health care costs is expected to grow in coming decades in line with projected increases in life expectancy and in the proportion of elderly people in Italy. It has been estimated that the indirect (productivity loss and informal care) and intangible (deterioration in health-related quality of life) costs of the disease will contribute to an increase in national health service expenditure, which will correspond to $1 \%$ of the total health care costs of the nation in the near future. The introduction of biological agents for the treatment of rheumatic diseases has resulted in an increase in the direct costs of RA; however, economic analyses that exclude indirect costs will underestimate the full economic impact of RA. The effectiveness of innovative therapies in preventing disease progression and functional impairment may, over time, attenuate the cost impact of RA in terms of hospitalizations and work absenteeism. Further research is needed to develop estimates of the economic impact of different therapeutic approaches in patients with RA in Italy, in order to provide tools that can drive the choice of the most cost-effective therapeutic option while maintaining high-quality care.
\end{abstract}

Keywords: rheumatoid arthritis, prevalence, disease costs, Italy

\section{Introduction}

Rheumatoid arthritis (RA) is a disabling and progressive chronic autoimmune disease that carries a significant burden. ${ }^{1}$ Although RA affects people of all ages, its prevalence increases with increasing age and it is more common in women than in men., ${ }^{2,3}$

A prevalence of $0.5 \%-1 \%$ and a mean annual incidence (ie, rate of new cases) of $0.02 \%-0.05 \%$ have been estimated in studies carried out in Northern Europe and in North America. ${ }^{4}$ The prevalence of RA in Southern Europe has been estimated to be lower than that in Northern Europe, with rates of $0.45 \%$ and $0.66 \%$ reported in the two areas, respectively. ${ }^{5}$ The annual incidence of RA is also lower in Southern than in Northern European countries. ${ }^{6}$

Estimates of prevalence are often very variable as a result of several factors, including the time period when the study was undertaken; the age distribution of the country reporting the estimates; differences in the health care organizations in the reporting countries; and the source of information. ${ }^{6}$ Similarly, changes in the epidemiology of RA are difficult to predict; while some studies might suggest a decline in incidence among countries with high rates of RA, ${ }^{5}$ other investigators suggest that the incidence 
is expected to increase in Europe because of the growing proportion of older people. ${ }^{7,8}$

RA is associated with a significant economic burden for patients, families, and health care systems. ${ }^{9}$ Moreover, an increase in the costs associated with RA is anticipated as a result of the aging population. ${ }^{7}$ There is a great amount of variability in estimates of the cost of RA across countries; these estimates are affected by methods of calculation, reimbursement policies, and availability (and time of availability) of drugs and social services. Differences in country-specific treatment guidelines on when to introduce newer costly drug classes (ie, biological agents) for patients with severe active and erosive disease also contribute to the variation in costs across the European Union (EU). ${ }^{6}$ However, the macroeconomic condition and the treatment guidelines remain the most important determinants that drive choice of therapy. ${ }^{6}$

Italy has the highest proportion of people aged 65 years or older in the EU and it has been estimated that, by 2029 , $25.7 \%$ of the population in Italy will be $\geq 65$ years. $^{7}$ Thus, the health care costs associated with age-related diseases like RA are likely to increase in Italy. The introduction of newer costly therapies may further contribute to the expected increase in the economic burden of RA in Italy.

This review aims to evaluate the economic impact of RA in Italy in the past two decades and to compare the costs of RA before and after the introduction of biological agents. In addition, the review will attempt to predict the future costs of RA in Italy, and to compare these costs with those in other European countries. While this is not designed as a "systematic review" as such, it does follow a similar procedure for identification of publications of relevance.

\section{Methods}

Comprehensive electronic searches of PubMed/Medline were performed using the search terms (in any field): prevalence OR cost AND rheumatoid arthritis AND Italy, with no language restriction. The search was limited to publications between January 1998 and December 2014.

The search identified 414 papers; abstracts of these publications were assessed for their relevance. In total, six papers reporting data on the prevalence of RA in Italy ${ }^{10-15}$ and four papers reporting economic data ${ }^{16-19}$ were initially considered as adequate for the objectives of this review. In addition, further data were extracted from the websites of Italian or European public health agencies and from Italian journals to add to the previously identified published literature on the health care costs of RA in Italy. This led to the inclusion of a further two articles ${ }^{6,20}$ that add important information on the past and current costs of RA in Italy, as well as on estimates of future costs.

\section{Prevalence of RA in Italy}

Previous studies have evaluated the prevalence of RA in Italy. The results from those studies that are available are summarized in Table 1. Although the small population samples and limited coverage of the studies do not allow a firm estimate of the national prevalence of the disease, the studies do give a rough idea of the likely prevalence and also highlight potential geographical variations.

A study ${ }^{10}$ undertaken in 1991-1992 in Chiavari, a small town located on the Ligurian coast, found that RA had a prevalence of $0.33 \%$ (95\% confidence interval [CI] $0.13-$ $0.53)$ in the general population, $0.13 \%(95 \%$ CI $0-0.31)$ in men, and $0.51 \%(95 \%$ CI $0.18-0.84)$ in women. This study included 3,294 individuals (73.9\% of those contacted), aged $\geq 16$ years, identified from four general practices. The mean age of subjects was 48.3 years, which may account for the relatively low prevalence reported in this study.

A higher prevalence of $0.46 \%$ (95\% CI 0.33-0.59) was reported in another study ${ }^{11}$ conducted from April 2004 to June 2004 in 2,155 subjects aged $\geq 18$ years in the Marche region. The mean age was 57.8 years and $53.4 \%$ of subjects were female. Similar estimates were reported from a survey conducted in 2002-2003 in Tempio Pausania (northern Sardinia) that involved 30,264 subjects aged $\geq 18$ years; ${ }^{12}$ prevalence was estimated to be $0.46 \%$ in the general population, $0.73 \%$ in women, and $0.19 \%$ in men.

Another study carried out in the province of Pisa in the years 2006 and $2007^{14}$ evaluated the prevalence of RA, the reliability of the RA diagnosis and prevalence estimated by general practitioners (GPs), and the economic impact of the disease in a total of 26,709 subjects aged over 18 years. Each GP completed a questionnaire on their patients; patients considered by GPs to have RA were then invited to attend an appointment at a specialist rheumatology center for confirmation or rejection of the diagnosis made. The estimated prevalence of correctly diagnosed RA was $0.51 \%$ (95\% CI $0.44-0.57)$ and the reliability of GPs when making a diagnosis of RA was $69 \%$ overall, although there was a high degree of heterogeneity among GPs.

Benucci et $\mathrm{l}^{13}$ evaluated the incidence of early RA (new cases) in a suburban area of Florence between September 2005 and August 2006 and suggested a rate of $0.98 \%$ (95\% CI $0.64-1.32 \%$ ) in the overall population, and $1.42 \%$ (95\% CI 0.85-1.99\%o) for females and 0.51\%o (95\% CI $0.16-0.87 \%$ ) for males. The mean age of newly diagnosed 


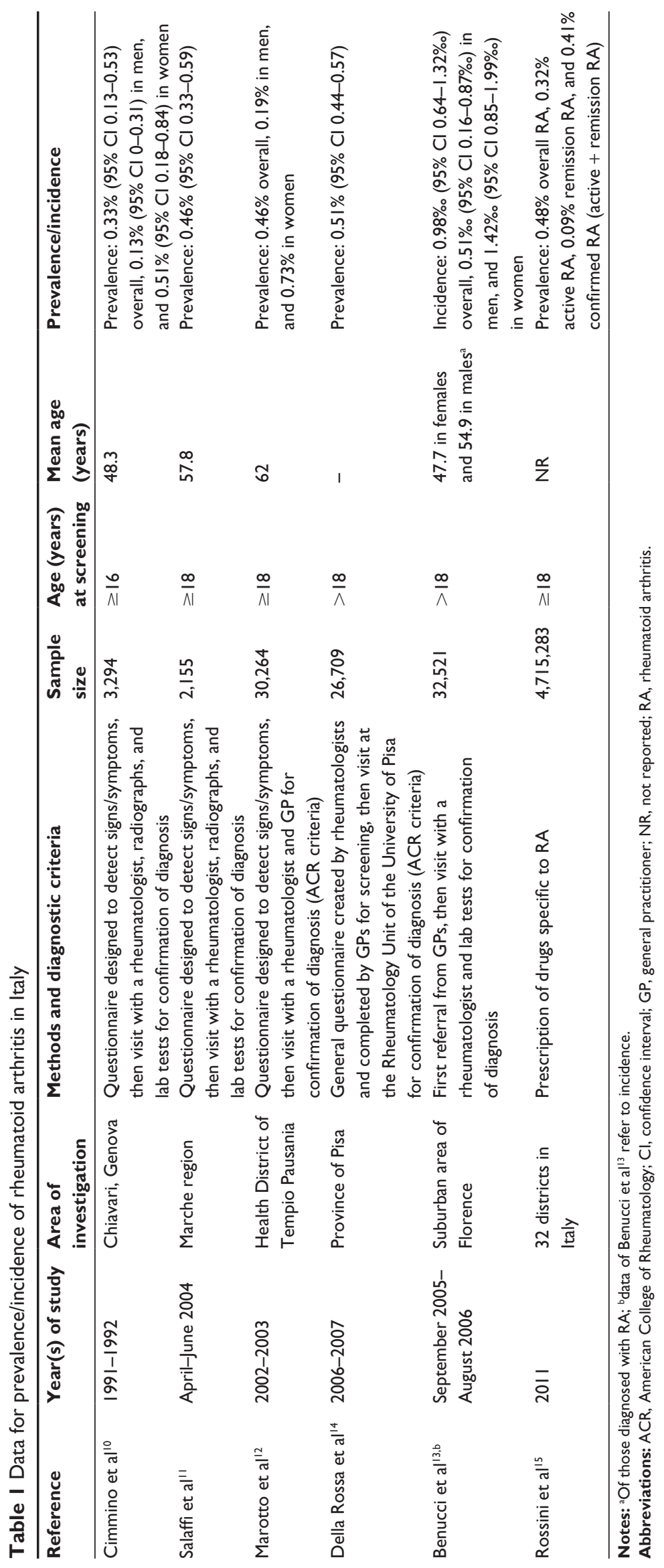


subjects was 47.7 years in females and 54.9 years in males. The incidence rate observed in this study was higher than that observed in other European countries, possibly due to tight adherence to diagnostic criteria for early RA and to the use of the criteria of the American College of Rheumatology $(\mathrm{ACR})^{21}$ as a method of assessment.

The most recent treatment-driven estimation of the prevalence and incidence of RA in Italy, performed in a cohort of 2,268,514 males and 2,446,769 females, and based on a diagnosis made according to prescription of at least three RA-specific drugs (corticosteroids, disease-modifying antirheumatic drugs, and biological agents), was calculated for the year 2011. ${ }^{15}$ Patients were classified as follows: those on specific drugs were classed as having active RA; those who had never had more than four prescriptions in the past were classed as unlikely RA; and those previously on chronic treatment but who had discontinued therapy for $>1$ year were classed as having RA in remission. A diagnosis of RA was made by a qualified specialist in a total of 22,801 of these subjects $(0.48 \%)$, with a prevalence of active RA, RA in remission, and confirmed RA (active + remission RA) of $0.32 \%, 0.09 \%$, and $0.41 \%$, respectively. The yearly incidence of active RA per 100,000 subjects was 48 (95\% CI 40-57) for females and 20 (95\% CI 10-30) for males. Both prevalence and incidence peaked around the eighth decade of life. The female:male ratio for both prevalence and incidence was $\sim 3.5: 1$ before the fifth decade of life and tended to decline to about $2: 1$ in subjects aged $>70$ years.

A modeling analysis of the prevalence of RA in 27 countries in the EU (plus Iceland, Norway, and Switzerland) conducted in $2008^{6}$ estimated that the overall prevalence of RA in Italy was $0.49 \%$ and was exactly the same as the calculated average prevalence in Europe. In this analysis, Italy was ranked as eighth in terms of estimated prevalence of RA and was one of four European countries (together with the UK, Sweden, and Germany) in which subjects aged $\geq 65$ years contributed more than $50 \%$ of the diagnosed cases of RA. The data also showed that Italy and Germany were the European countries with the highest proportion of people aged $\geq 65$ years. Taken together, these data ${ }^{6}$ suggest that the prevalence of RA will further increase in Europe and in Italy in line with projected increases in the elderly population.

\section{Costs of RA in Italy}

\section{Past costs}

Few studies have estimated the costs associated with RA in Italy before the availability of biological agents.
A retrospective, prevalence-based, multicenter, cost-of-illness study, undertaken in 1998 in ten rheumatology institutes located in northern, central, and southern Italy, ${ }^{19}$ evaluated the direct (hospitalizations, specialist visits, treatments, diagnostics, and nonmedical costs), indirect (productivity loss and informal care), and intangible (deterioration in healthrelated quality of life [HRQOL] of patients, their families, and their friends) costs associated with RA in 200 patients aged 18-65 years. Participants were categorized into four classes of severity according to the ACR RA functional status index in place at the time of the study. ${ }^{22}$ The results showed that indirect costs accounted for the largest part of the disease management costs and that social costs (direct plus indirect costs) increased as RA worsened. The calculated average annual cost for each patient varied significantly depending on disease severity and correlated with the Health Assessment Questionnaire Disability Index ${ }^{23}$ and ACR criteria. ${ }^{22}$ Total costs ranged from $€ 3,718.3$ for patients in functional class I to $€ 22,946.0$ for patients in class IV. Both the direct costs (respectively, $€ 1,643.4$, €2,910.2, €4,236.5, and $€ 5,696.8$ per patient from class I to class IV) and the indirect costs $(€ 2,074.9, € 9,566.4, € 12,183.1$, and $€ 17,249.2$ per patient, respectively) over the 12 months of observation increased significantly $(P<0.0005)$ across the four functional classes. Social costs were significantly higher in patients with other concomitant diseases. Female sex was also associated with higher costs.

The modeling study conducted in $2008^{6}$ used a specifically developed model to estimate the total cost of RA in Europe. Costs, extracted from the studies identified in a comprehensive literature review, were separated into different categories: medical costs, drugs, nonmedical costs, informal care costs, and indirect costs, and inflated to 2008 values. The estimated costs per patient were then combined with country- and agespecific prevalence data to obtain a figure for the total cost of RA in each country. The mean estimated annual cost per patient in Europe with RA was $€ 12,902$, with a clear difference between Western Europe (mean €14,997) and Central/ Eastern Europe (mean $€ 3,752$ ). The total mean annual cost of the disease across all European countries was estimated at about $€ 25.1$ billion. The estimated mean annual cost per patient in the study countries ranged from about $€ 2,000$ to $€ 21,000$, the estimated mean annual cost per patient in Italy was $€ 11,546$ in line with the mean for Europe as a whole. In Italy, mean costs were estimated at $€ 4,552$ for direct costs (excluding biological agents), €731 for biological agents, $€ 3,290$ for informal care, and $€ 2,972$ for indirect costs. This distribution indicates that, at the time of this modeling study 
(2008), direct costs in Europe overall represented 43\% of the total expenditure. Notably, at the time of the analysis, Italy and Germany had the lowest use of biologics in Western Europe due to tight budget control policies. For example, in Italy, biologics could only be prescribed in the hospital setting and use of such drugs was limited to a small percentage of the total expenditure. ${ }^{6}$ Despite individual differences in costs between countries, costs outside the health care sector, such as informal care and productivity loss, represented the greater part of the costs of RA in all countries. ${ }^{6}$

\section{Current costs}

The structure of the costs of RA has changed over the years, with a substantial increase in the direct costs of the disease largely as a result of the availability of newer, more costly biological agents. For example, in France, the direct annual costs of RA were estimated to be $€ 4,000$ in 2000 (before the introduction of biological agents) $)^{24}$ and about $€ 12,000$ in a 2005 study in which $20 \%$ of patients were receiving these agents. ${ }^{25}$ Although the introduction of biological agents has contributed to increased direct medical costs, ${ }^{26,27}$ their use is associated with marked improvements in disease activity, joint damage, and loss of productivity. ${ }^{18}$ Furthermore, data from the Consortium of Rheumatology Researchers of North America registry have shown that the use of biological agents is associated with a reduction in the risk of cardiovascular events in patients with RA. ${ }^{28}$

In a health economic analysis carried out in the province of Pisa in the years 2006 and 2007, ${ }^{14}$ the mean annual cost per patient with RA was estimated to be $€ 5,878$ (median $€ 6,434$; interquartile range $€ 669-€ 7,052$ ), with high variability, mainly depending on the degree of disability. In this analysis, more than $90 \%$ of the overall annual cost per patient was due to the medical and nonmedical components of direct costs.
A more recently published literature review ${ }^{16}$ evaluated the mean annual social costs per patient and the total social cost of RA in the last decade in Italy. Data from each study (Table 2), when further analyzed, showed that the mean annual social cost (ie, overall direct plus indirect costs) of RA was $€ 13,595$ per adult patient (2012 values). Based on prevalence data, it was estimated that RA resulted in a total social cost of $€ 3.5$ billion in Italy per year. Direct medical costs accounted for $21 \%$ of the total costs, while the remaining $79 \%$ were nonmedical costs (direct nonmedical costs and indirect costs). Nonmedical and indirect costs were mainly sustained by individual households for informal care ( $40 \%$ of the total cost), and by the economy (due to absence from work of patients and caregivers; $31 \%$ of the total cost). Based on these data, it is evident that assessment of the economic burden of RA based solely on the evaluation of direct medical costs gives a limited view of the total economic burden of the disease.

\section{Estimated future costs}

Italy has the second highest percentage of population $\geq 65$ years of age in the world, ${ }^{29}$ therefore, an increase in the costs of RA in Italy is expected due to the aging population. Since mean costs per patient increase with increasing functional disability, reliable health-economic evaluations should estimate the long-term consequences of the changing course of the disease and the effects of preventing or delaying the development of severe disability. ${ }^{30}$ Short-term analyses may be misleading as they tend to neglect the importance of modifications in the course of the disease as a result of treatment intervention and its positive impact on the deterioration of HRQOL.

A systematic literature review ${ }^{18}$ on the economic consequences of, and pharmacoeconomic issues relating to, RA, based on a total of 127 published articles, has shown that disease

Table 2 Mean annual health care system and patient costs per patient with rheumatoid arthritis (inflated to Euro 20I2), as estimated by the studies included in an Italian literature review

\begin{tabular}{|c|c|c|c|c|c|c|c|c|c|c|}
\hline \multirow{2}{*}{$\begin{array}{l}\text { Reference } \\
\text { Perspective of analysis }\end{array}$} & \multicolumn{2}{|c|}{$\begin{array}{l}\text { Leardini } \\
\text { et } \mathrm{al}^{19, \mathrm{a}}\end{array}$} & \multirow{2}{*}{\multicolumn{2}{|c|}{$\begin{array}{l}\text { Osservatorio } \\
\text { Sanità e Salute }^{2} \\
\text { Social }\end{array}$}} & \multirow{2}{*}{\multicolumn{2}{|c|}{$\begin{array}{l}\text { Censis- } \\
\text { ANMAR-SIR }{ }^{45} \\
\text { Patient }\end{array}$}} & \multirow{2}{*}{\multicolumn{2}{|c|}{$\begin{array}{l}\text { Della Rossa } \\
\text { et al }{ }^{14} \\
\text { Social }\end{array}$}} & \multirow{2}{*}{\multicolumn{2}{|c|}{$\begin{array}{l}\text { Cerra et al }{ }^{44} \\
\text { Health care } \\
\text { system }\end{array}$}} \\
\hline & \multicolumn{2}{|l|}{ Social } & & & & & & & & \\
\hline Cost items & Euro & $\%$ & Euro & $\%$ & Euro & $\%$ & Euro & $\%$ & Euro & $\%$ \\
\hline Direct costs & 10,726 & 63 & 3,630 & 33 & 5,891 & 48 & 6,233 & 97 & 902 & 100 \\
\hline Medical direct costs & 3,225 & 19 & 3,630 & 33 & 771 & 6 & 2,405 & 38 & 3,902 & 100 \\
\hline Nonmedical direct costs & 7,501 & 44 & - & - & 5,120 & 42 & 3,828 & 59 & - & - \\
\hline Indirect costs & 6,229 & 37 & 7,367 & 67 & 6,450 & 52 & $215^{b}$ & 3 & - & - \\
\hline Total costs & 16,995 & 100 & 10,997 & 100 & $|2,34|$ & 100 & 6,448 & 100 & 3,902 & 100 \\
\hline
\end{tabular}

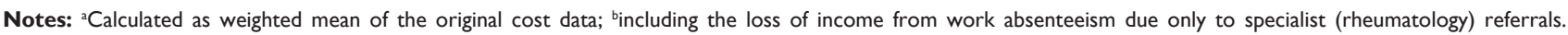
Copyright (@) 20I3. Turchetti G, Bellelli S, Mosca M. The social cost of rheumatoid arthritis in Italy: the results of an estimation exercise. Reumatismo. 20I4;65(6):27I-277.16 Abbreviation: SIR, Italian Society of Rheumatology. 
severity, functional disability, age, and socioeconomic status are the most relevant predictors of cost increase in RA.

A published editorial ${ }^{20}$ has estimated the economic impact of RA in Italy over the next 30 years using cost-of-illness modeling. This analysis assumed that the costs of RA varied as the disease evolved, and classified disease by stage according to the Steinbrocker radiological classification. ${ }^{31}$ Using inferential statistical methods, the probability of evolution toward a more severe stage of the disease in the absence of treatment was estimated. A total of 411,692 patients with RA were classified according to the four stages of the disease and their progression over the next 30 years was simulated. The results showed that, in the next 30 years, the annual cost of RA will increase from $€ 3.3$ billion (for 2009) to a peak of $€ 4$ billion (for 2029), including both direct and indirect costs. Cost estimates will vary between regions, with higher costs estimated in Lombardy (€430-€500 million), Lazio (€300-€330 million), Sicily (€238-€281 million), and EmiliaRomagna (€131-€187 million). This suggests that costs will be only partially correlated with the number of inhabitants in different Italian regions and will possibly depend on differing regional health care policies. Expenditure will not greatly differ between workers (from $€ 320$ million in 2009 to $€ 420$ million in 2029) and homemakers (from €318 million in 2009 to $€ 421$ million in 2029). The disease was also estimated to have a significant impact on costs due to loss of productivity that are supported by the Italian National Health care System (NHS), which are predicted to increase from $0.67 \%$ of total social security spending in 2009 to $0.7 \%$ of this spending in 2029. In addition, RA was predicted to account for a total of $1 \%$ of all NHS costs in 2029 . These data indicate that the costs associated with untreated RA would make a significant contribution to NHS and societal costs in the next decades, thus confirming that delaying early diagnosis and intervention will result in increased overall costs for the community.

The development of biosimilar biologics may alter the landscape of biologics and their associated costs in the future. Physicians' attitudes toward the interchangeability of drugs, indications from regulatory authorities, and national recommendations will have a major impact on the use of biosimilars in the management of RA. While, a statement position from the Italian Society of Rheumatology has raised concerns about the true equivalence of biosimilars in rheumatic diseases and hence on the potential for interchangeability of drugs, studies in RA currently support the similarity of biosimilars and their originators. ${ }^{32}$ Furthermore, as biologics require a more sophisticated manufacturing process than that of existing conventional medications, tight regulation will be required to avoid any possible additional safety risks to make these agents truly cost-effective. ${ }^{33}$

\section{Discussion}

The studies conducted to date have indicated that the prevalence of RA in Italy is $\sim 0.5 \%$. Although most of these studies have been undertaken in small communities or at a regional level, and are therefore poorly representative of the national situation, the calculated prevalence has not changed over the years.

The largest of the studies on the prevalence and incidence of RA in Italy, ${ }^{15}$ which involved more than 4.5 million people, has clearly indicated that both the prevalence and incidence of RA progressively increase in both men and women up to the age of 80 years. As Italy is undergoing a process of demographic transition, in which higher life expectancy will lead to a dramatic increase in the number of elderly people in the near future, ${ }^{7}$ it is expected that RA will impose a heavy socioeconomic burden on the NHS in coming years.

It is well established that costs associated with RA are likely to rise as the disease progresses, accompanied by a substantial reduction in HRQOL. ${ }^{17}$ As in other disabling diseases, much of the cost of RA occurs outside the health care system, because it is associated with loss of work capability and the need for informal care in the later stages of the disease. ${ }^{25}$ The severity and the progression of RA have a great influence on the costs of the disease. Disease progression is associated with increasing functional impairment and reduced HRQOL, which may lead to work absenteeism and inability and hence increased indirect costs, which are estimated to be twice as high as direct costs when the disease progresses. ${ }^{34,35}$

The introduction of biological drugs for the treatment of RA highlights the role of economics in the considerations for patient access to innovative but expensive treatments. Inclusion in the reimbursement system is a very important condition for access to innovative treatments. Cost-effectiveness is a further criterion to fulfill, in addition to a favorable risk-benefit profile, for marketing approval by the European Medicines Agency and national medicines agencies.

Health-economic analyses conducted on a cross-sectional basis or over a short-term period reflect differences in the costs of drugs and are less sensitive to the long-term evolution of the disease in terms of its impact on social costs and loss of productivity. Therefore, a reliable estimate of the cost-effectiveness of a drug class should not be based solely on the net costs of the compounds, but should also take into consideration the effects of such drugs on the progression of the disease, as rapid/severe progression can lead to huge increases in indirect social costs and loss of 
productivity. In fact, the use of biologics in the early stage of RA may reduce other health care costs by slowing the evolution of the disease. The extent to which the high direct costs incurred from early use of biologics may be balanced in part by other health care cost offsets due to the reduction in the need for surgery or other interventions beyond the fourth year of the disease, remains to be elucidated. ${ }^{36}$

Although cost-benefit and cost-effectiveness analyses are recognized as standard techniques for pharmacoeconomic evaluations, other methods, such as the cost-utility analysis, are better tailored to evaluate the health improvement attributable to a treatment, in which health improvement is generally measured in quality-adjusted life-years (QALYs) gained. ${ }^{37}$ In particular, the QALY combines life expectancy and HRQOL by weighing life-years with a quality index named utility. As HRQOL is among the most important outcomes in RA, in which it is difficult to simply study morbidity and mortality, interest has been focused on how well the different treatment programs improve patients' physical functioning, social functioning, and psychological well-being. Accurate pharmacoeconomic estimates may drive the use of new and more expensive therapies in the treatment of RA and help health care providers and budget holders to choose the most effective strategies for patients. Several factors should be considered in cost-effectiveness analyses of RA treatments. Analyses should not be focused only on the effects of a therapy on the onset of disability and the progression of joint destruction, but also on the adverse event profile of the drug and on its efficacy and safety over the long term, which are generally not investigated in randomized clinical trials. Pharmacoeconomic analysis of the existing therapies for RA should be based on the awareness that treatment will prevent progression to the next level of disease severity or that the disease will take longer to progress, thus avoiding or delaying the high costs associated with more severe stages of the disease. ${ }^{38}$ This will help attenuate the impact on indirect and social costs due to disease progression and, most importantly, on the intangible costs due to the progression of the disease and associated comorbidities over the years. Indeed, there is a high prevalence of comorbidities and their associated risk factors among RA patients, as shown in a recent international observational study conducted in 17 countries worldwide. ${ }^{39}$ The study has shown a high intercountry variability in the prevalence of comorbidities in RA and suggests that the diagnosis and management of such comorbidities is far from optimal. Depression (15\% of patients on average across countries) was the most commonly observed comorbidity, followed by asthma (6.6\%), gastrointestinal ulcer (10.8\%), ischemic cardiovascular disease $(6.0 \%)$, and solid tumors (4.5\%). Italy had the highest prevalence of hepatitis B $(9.0 \%)$ and $\mathrm{C}(6.6 \%)$, rate of patients with $>40$ skin nevi $(12 \%)$ and of Framingham score $>20 \%$ (59\%). The prevalence rate of depression was also above average in Italy (19\%). Although the high prevalence of some of these comorbidities may be related to the medications used (eg, corticosteroids) or to traditional risk factors (eg, tobacco smoking), some others (eg, depression) may be a direct consequence of systemic inflammation and its associated symptoms and effect on HRQOL. ${ }^{40} \mathrm{~A}$ task force of the ACR and the European League Against Rheumatism has recently highlighted the importance of comorbidities in the management of RA and in the treatment decision-making strategies. ${ }^{41}$ While the use of biologic response modifiers is not associated with an increased risk of malignancy, ${ }^{42}$ improvements in disease activity following 1-year treatment with biologic agents is associated with important gains in terms of QALYs and HRQOL, ${ }^{43}$ suggesting that successful treatment of RA can result in lower levels of depression.

The recent published editorial ${ }^{20}$ on the 30 -year costs of untreated RA in Italy, which has shown that actual costs may rise in the coming years if the disease is not managed, highlights that costly interventions aimed at sparing future expenses are of particular relevance in countries like Italy, where RA and associated comorbidities will make a significant contribution to the economic burden for the NHS, given the increased proportion of elderly people expected in years to come.

Further research is needed to develop estimates of the economic impact of different therapeutic approaches in patients with RA in Italy. In particular, accurate pharmacoeconomic analyses would be valuable to help guide treatment decisions, ensuring effective spending without compromising the quality of care delivered.

\section{Acknowledgments}

The authors would like to thank Luca Cantini and Clare Gurton (Rx Communications, Mold, UK) for medical writing assistance with the preparation of this article, funded by Eli Lilly and Company.

\section{Authors' contributions}

All authors made substantial contributions to conception and design, acquisition of data, or analysis and interpretation of data; took part in either drafting the article or revising it critically for important intellectual content; gave final approval of the version to be published; and agree to be accountable for all aspects of the work. 


\section{Disclosure}

VR and VH are employees of Eli Lilly and Company. PSP has received payment from Eli Lilly and Company to serve on an Advisory Board. AM, FA, and MB have no conflicts of interest.

\section{References}

1. Cross M, Smith E, Hoy D, et al. The global burden of rheumatoid arthritis: estimates from the global burden of disease 2010 study. Ann Rheum Dis. 2014;73(7):1316-1322.

2. Osservatorio Sanità e Salute. Progetto di ricerca: costo sociale malattie reumatiche. Convegno "Malattie Reumatiche: disabilità, impatto sul lavoro e costi". [Health and Health Observatory. Research project: social cost of rheumatic diseases. Conference "Rheumatic Diseases: disability, impact on work and costs]. Roma: Osservatorio Sanità e Salute 2008 Dec 4. Italian.

3. European Musculoskeletal Conditions Surveillance and Information Network (eumusc.net). Musculoskeletal Health in Europe Report v5.0. Available from: http://www.eumusc.net/myUploadData/ files/Musculoskeletal\%20Health\%20in\%20Europe\%20Report\%20v5. pdf. Accessed November 3, 2014.

4. Alamanos Y, Drosos AA. Epidemiology of adult rheumatoid arthritis. Autoimmun Rev. 2005;4(3):130-136.

5. Alamanos Y, Voulgari PV, Drosos AA. Incidence and prevalence of rheumatoid arthritis, based on the 1987 American College of Rheumatology criteria: a systematic review. Semin Arthritis Rheum. 2006; 36(3):182-188.

6. Kobelt G, Kasteng F. Access to innovative treatments in rheumatoid arthritis in Europe. European Federation of Pharmaceutical Industry Associations (EFPIA); 2009. Available from: http://www.comparatorreports.se/Access \%20to\%20RA\%20Treatments\%20October\%202009. pdf. Accessed November 18, 2015.

7. European Commission, Economic Policy Committee. The 2012 Ageing Report: Underlying Assumptions and Projection Methodologies. European Economy 4/2011. European Commission Directorate-General for Economic and Financial Affairs. 2011. Available from: http:// ec.europa.eu/economy_finance/publications/european_economy/2011/ pdf/ee-2011-4_en.pdf. Accessed May 3, 2015.

8. Reginster JY. The prevalence and burden of arthritis. Rheumatology (Oxford). 2002;41(Suppl 1):3-6.

9. Boonen A, Severens JL. The burden of illness of rheumatoid arthritis. Clin Rheumatol. 2011;30(Suppl 1):S3-S8.

10. Cimmino MA, Parisi M, Moggiana G, Mela GS, Accardo S. Prevalence of rheumatoid arthritis in Italy: the Chiavari Study. Ann Rheum Dis. 1998;57(5):315-318.

11. Salaffi F, De Angelis R, Grassi W; MArche Pain Prevalence; INvestigation Group (MAPPING) study. Prevalence of musculoskeletal conditions in an Italian population sample: results of a regional community-based study. I. The MAPPING study. Clin Exp Rheumatol. 2005;23(6):819-828.

12. Marotto D, Nieddu ME, Cossu A, Carcassi A. Prevalenza dell'artrite reumatoide nel Nord Sardegna: lo studio di Tempio Pausania [Prevalence of rheumatoid arthritis in North Sardinia: the Tempio Pausania's study]. Reumatismo. 2005;57(4):273-276. Italian.

13. Benucci M, Cammelli E, Manfredi M, Saviola G, Baiardi P, Mannoni A; Associazione Medici-Scandicci. Early rheumatoid arthritis in Italy: study of incidence based on a two-level strategy in a sub-area of Florence (Scandicci-Le Signe). Rheumatol Int. 2008;28(8):777-781.

14. Della Rossa A, Neri R, Talarico R, et al. Diagnosis and referral of rheumatoid arthritis by primary care physician: results of a pilot study on the city of Pisa, Italy. Clin Rheumatol. 2010;29(1):71-81.

15. Rossini M, Rossi E, Bernardi D, et al. Prevalence and incidence of rheumatoid arthritis in Italy. Rheumatol Int. 2014;34(5): 659-664.
16. Turchetti G, Bellelli S, Mosca M. The social cost of rheumatoid arthritis in Italy: the results of an estimation exercise. Reumatismo. 2014;65(6):271-277.

17. Iannazzo S, De Francesco M, Gomez-Ulloa D, Benucci M. A review of cost-effectiveness evaluations as part of national health technology assessments of biologic DMARDs in the treatment of rheumatoid arthritis. Expert Rev Pharmacoecon Outcomes Res. 2013;13(4):455-468.

18. Furneri G, Mantovani LG, Belisari A, et al. Systematic literature review on economic implications and pharmacoeconomic issues of rheumatoid arthritis. Clin Exp Rheumatol. 2012;30(4 Suppl 73):S72-S84.

19. Leardini G, Salaffi F, Montanelli R, Gerzeli S, Canesi B. A multicenter cost-of-illness study on rheumatoid arthritis in Italy. Clin Exp Rheumatol. 2002;20(4):505-515.

20. Medicinae Doctor Editors. Impatto economico delle malattie reumatiche. [Economic impact of rheumatic diseases]. MD Medicinae Doctor - Anno XVI numero 23-23 giugno 2009, page 31. Passoni Editore. Italian.

21. Arnett FC, Edworthy SM, Bloch DA, et al. The American Rheumatism Association 1987 revised criteria for the classification of rheumatoid arthritis. Arthritis Rheum. 1988;31(3):315-324.

22. Hochberg MC, Chang RW, Dwosh I, Lindsey S, Pincus T, Wolfe F. The American College of Rheumatology 1991 revised criteria for the classification of global functional status in rheumatoid arthritis. Arthritis Rheum. 1992;35(5):498-502.

23. Fries JF, Spitz P, Kraines RG, Holman HR. Measurement of patient outcome in arthritis. Arthritis Rheum. 1980;23(2):137-145.

24. Guillemin F, Durieux S, Daurès JP, et al. Costs of rheumatoid arthritis in France: a multicenter study of 1109 patients managed by hospitalbased rheumatologists. J Rheumatol. 2004;31(7):1297-1304.

25. Kobelt G, Jönsson B. The burden of rheumatoid arthritis and access to treatment: outcome and cost-utility of treatments. Eur J Health Econ. 2008;8(Suppl 2):95-106.

26. Doan QV, Chiou CF, Dubois RW. Review of eight pharmacoeconomic studies of the value of biologic DMARDs (adalimumab, etanercept, and infliximab) in the management of rheumatoid arthritis. J Manag Care Pharm. 2006;12(7):555-569.

27. Nam JL, Ramiro S, Gaujoux-Viala C, et al. Efficacy of biological disease-modifying antirheumatic drugs: a systematic literature review informing the 2013 update of the EULAR recommendations for the management of rheumatoid arthritis. Ann Rheum Dis. 2014; 73(3):516-528.

28. Greenberg JD, Kremer JM, Curtis JR, et al; CORRONA Investigators. Tumour necrosis factor antagonist use and associated risk reduction of cardiovascular events among patients with rheumatoid arthritis. Ann Rheum Dis. 2011;70(4):576-582.

29. United Nations, Department of Economic and Social Affairs, Population Division. World Population Ageing 2013. Report No ST/ESA/ SER.A/348. 2013. Available from: http://www.un.org/en/development/ desa/population/publications/pdf/ageing/WorldPopulationAgeing2013. pdf. Accessed November 5, 2014.

30. Kobelt G. Health economic issues in rheumatoid arthritis. Scand $J$ Rheumatol. 2006;35(6):415-425.

31. Steinbrocker O, Traeger $\mathrm{CH}$, Batterman RC. Therapeutic criteria in rheumatoid arthritis. J Am Med Assoc. 1949;140(8):659-662.

32. Fiorino G, Girolomoni G, Lapadula G, et al. The use of biosimilars in immune-mediated disease: a joint Italian Society of Rheumatology (SIR), Italian Society of Dermatology (SIDeMaST), and Italian Group of Inflammatory Bowel Disease (IG-IBD) position paper. Autoimmun Rev. 2014;13(7):751-755.

33. Kukar M, Petryna O, Efthimiou P. Biological targets in the treatment of rheumatoid arthritis: a comprehensive review of current and in-development biological disease modifying anti-rheumatic drugs. Biologics. 2009;3:443-457.

34. Emery P, Kosinski M, Li T, et al. Treatment of rheumatoid arthritis patients with abatacept and methotrexate significantly improved health-related quality of life. J Rheumatol. 2006;33(4):681-689. 
35. Pugner KM, Scott DI, Holmes JW, Hieke K. The costs of rheumatoid arthritis: an international long-term view. Semin Arthritis Rheum. 2000;29(5):305-320.

36. Chevreul K, Haour G, Lucier S, et al. Evolution of direct costs in the first years of rheumatoid arthritis: impact of early versus late biologic initiation - an economic analysis based on the ESPOIR cohort. PLoS One. 2014;9(5):e97077.

37. Turchetti G, Scalone L, Della Casa Alberighi O, et al. The rationale of pharmacoeconomic analysis in rheumatologic indications. Clin Exp Rheumatol. 2012;30(4 Suppl 73):S64-S71.

38. Benucci M, Saviola G, Manfredi M, Sarzi-Puttini P, Atzeni F. Cost effectiveness analysis of disease-modifying antirheumatic drugs in rheumatoid arthritis. A systematic review literature. Int $J$ Rheumatol. 2011;2011:845496.

39. Dougados M, Soubrier M, Antunez A, et al. Prevalence of comorbidities in rheumatoid arthritis and evaluation of their monitoring: results of an international, cross-sectional study (COMORA). Ann Rheum Dis. 2014;73(1):62-68.

40. Margaretten M, Julian L, Katz P, Yelin E. Depression in patients with rheumatoid arthritis: description, causes and mechanisms. Int J Clin Rheumatol. 2011;6(6):617-623.
41. Smolen JS, Breedveld FC, Burmester GR, et al. Treating rheumatoid arthritis to target: 2014 update of the recommendations of an international task force. Ann Rheum Dis. Epub 2015 May 12.

42. Lopez-Olivo MA, Tayar JH, Martinez-Lopez JA, et al. Risk of malignancies in patients with rheumatoid arthritis treated with biologic therapy: a meta-analysis. JAMA. 2012;308(9):898-908.

43. Linde L, Sørensen J, Østergaard M, Hetland ML. Gain in qualityadjusted life-years in patients with rheumatoid arthritis during 1 year of biological therapy: a prospective study in clinical practice. J Rheumatol. 2013;40(9):1479-1486.

44. Cerra C, Ravasio R, Polcaro F. Il costo dell'Artrite Reumatoide: l'esperienza dell'ASL della Provincia di Pavia. [The cost of Rheumatoid Arthritis: the experience of the ASL of the Province of Pavia]. Giorn It. Health Technol Assess. 2009;(2):111-117. Italian.

45. Censis-ANMAR-SIR. Un percorso ad ostacoli. Primo rapporto sociale sull'artrite reumatoide. [An obstacle course. First social report on rheumatoid arthritis]. 2008. Available from: http:/www.anmar-italia.it/ cosa-facciamo/appuntamenti/193-qun-percorso-ad-ostacoliq. Accessed July 22, 2013. Italian.
ClinicoEconomics and Outcomes Research

\section{Publish your work in this journal}

ClinicoEconomics \& Outcomes Research is an international, peerreviewed open-access journal focusing on Health Technology Assessment, Pharmacoeconomics and Outcomes Research in the areas of diagnosis, medical devices, and clinical, surgical and pharmacological intervention. The economic impact of health policy and health systems

\section{Dovepress}

organization also constitute important areas of coverage. The manuscript management system is completely online and includes a very quick and fair peer-review system, which is all easy to use. Visit http://www.dovepress.com/testimonials.php to read real quotes from published authors. 